\title{
A Sociology for Other Animals: Analysis, advocacy, intervention
}

\section{Introduction}

Sociology has come late to the field of Human Animal Studies (HAS), and such scholarship remains peripheral to the discipline. Early sociological interventions in the field were often informed by a critical perspective, in particular feminism but also Marxism and critical race studies. There have also been less critical routes taken, often using approaches such as actor-network theory and symbolic interactionism. These varied initiatives have made important contributions to the project of animalizing sociology and problematizing its legacies of human-exclusivity. As HAS expands and matures however, different kinds of study and different normative orientations have come increasingly into relations of tension in this eclectic field. This is particularly so when it comes to the ideological and ethical debates on appropriate human relations with other species, and on questions of whether and how scholarship might intervene to alter such relations. However, despite questioning contemporary social forms of human-animal relations and suggesting a need for change, the link between analysis and political strategy is uncertain.

This paper maps the field of sociological animal studies through some examples of critical and mainstream approaches and considers their relation to advocacy. While those working in critical sociological traditions may appear to have a more certain political agenda, this article suggests that an analysis of 'how things are' does not always lead to a coherent position on 'what is to be done' in terms of social movement agendas or policy intervention. In addition, concepts deployed in advocacy such as rights, liberation and welfare are problematic when applied beyond the human. Even conceptions less entrenched in the liberal humanist tradition such as embodiment, care and vulnerability are difficult to operationalize. 
Despite complex and contested claims however, this paper suggests that there might also be possibilities for solidarity.

\section{Critical sociologies and animal studies}

It is only relatively recently that influential voices have been heard to argue that sociology must fully embrace the world of non-human beings, objects and things and the ways our lives are constituted with them (Latour, 2010: 75-78). These critiques have helped to open up the discipline to new areas of concern, such as animal studies, with recent sociological work in animal studies further destabilising our certainties of the 'social' (Carter and Charles, 2011; Taylor and Signal, 2011). Sociological interest in non-human animals has also been brought into view through more established sub-areas such as science and technology studies (Twine, 2010), food and eating (Cole and Stewart, 2009) or the family (Aull-Davies and Charles, 2008). It is important to remember however that interrogating naturalised categories has been a sociological preoccupation, and thus sociology lends itself to problematizing the human/non-human animal binary and the ways this is played out in social formations. In addition, species is constituted by and through 'human' hierarchies - ideas of animality and of 'nature' are vitally entangled in the constitution of 'race', gender, class and other 'human' differences with which critical sociologies have well established concern. As Burowoy (2005: 268) has argued, it is critical sociologies which often draw attention to the omissions of the disciplinary mainstream and identify new subjects and objects for study. Twine (2010: 8) has suggested that sociological animal studies might be understood in Burowoy's terms as a 'critical sociology'.

While human-animal studies may be new, and raise questions for the disciplinary mainstream, simply including non-human animals as a sociological subject does not a critical sociology make however. In the tradition of C. Wright 
Mills, critical sociology has tended to argue that sociology must be 'for' something, and be used to advocate for social change (Geary, 2009). Mills was deeply opposed to the mainstream of the discipline which claimed objectivity and disinterested observation while functioning to validate the status quo (see Mills 2000: 25-49). For Mills, the politically committed sociologist reveals the 'way things are'. Through this process of critical investigation, such sociology reveals a world of possibility and suggests paths for intellectual engagement and intervention (Summers, 2008).

Peggs (2014: 42) suggests that sociological animal studies is likely to be associated with advocacy, for "In the light of the oppression of billions upon billions of non-human animals, how can the study of 'human' 'animal' relations fail to be politically engaged?". Despite this, some scholarship can, and has been, disengaged because the 'bringing in' of animals as new subjects of sociological study has been via both mainstream and critical routes. On the one hand, we have a sociology which includes non-human animals and human-animal relations as worthy of sociological attention. On the other, we have sociological animal studies which raises questions about the exploitation and oppression of non-human animals, and is more reflective of critical traditions in sociological enquiry. This is not to say that critical sociologies are not resistant to the study of non-human animals, shaped by the belief that studying non-human animals lessens or undermines the notion of oppression, however. This, Wilkie (2013: 3) has suggested, is because for various reasons (inter and transdisciplinarity, a more-than-human focus, politicisation) association with HAS scholarship is "academically contaminat[ing]" and can tarnish professional credibility. Researching in a field of multiple species is a deviant practice and scholarship may be received by the mainstream as trivial or treated with derision, perhaps seen as 'risky' (Shapiro and de Mello, 2010: 167-70; Kruse, 2002: 337).

Despite such marginality and marginalization, we have seen a rapid expansion of this 'deviant' field of social scientific enterprise such that humananimal studies has become "everything to everyone" (Best, 2009: 13). For some 
scholarship, relationships with activism are imperative, for others, a normative commitment to emancipatory sociology (whether or not it is specifically allied with activism) is what is key (Aaltola, 2011; Peggs, 2012). The development of Critical Animal Studies (CAS) in the early 2000s led to a strengthening of arguments for interested or engaged theory that in Mills sense is 'for' something, in this case, for the 'liberation' of non-human and increasingly also, human animals (Nocella II, Sørenson, Socha and Matsuoka, 2014; Taylor and Twine, 2014). CAS differentiates itself from Mainstream Animal Studies (MAS) by its focus on a politics of animal liberation that is critical of the intersected and co-constituted qualities of oppression and promotes an "interspecies alliance politics" (Best, 2006). Scholarly work in CAS is not disinterested, but clearly addresses an emancipatory agenda whereas MAS scholarship tends to be reformist and non-emancipatory. For Twine (2010: 8) however, the boundaries between CAS and MAS are blurred and the work of individual scholars is not always easy to pin down in terms of this divide; and Wilkie (2013: 11) suggests we might have a more dynamic view of the field with scholarship located along a MAS-CAS continuum depending on particular arguments made and subjects focused upon in particular work. Wilkie adds a further category of 'radical animal studies' (RAS) beyond CAS on her continuum (Wilkie, 2013: 14). This reflects the suggestion made by Best (2006) that the increasing mainstreaming of CAS undermines the radicalism of its analysis and its politics, and that animal liberation scholarship might need to further differentiate itself in a subfield of 'radical animal studies'. Wilkie's continum model of the field is to be commended, but it is difficult to see quite where feminist scholarship in animal studies (FAS) fits. Some FAS scholarship emerges from the broader field of ecofeminism (Author, forthcoming) and reflects a concern with intersectionality that informed the development of CAS (Best et al., 2009). Yet while clearly politically motivated, FAS scholarship is eclectic, and not always congruent with the leftliberation activism of much CAS scholarship. 
Linear continuums do not adequately capture the complexities of tension and inter-relation in this rapidly emerging field, yet taxonomies of MAS, CAS and FAS do function as useful shorthand for outlining analytic positions. The next section outlines some examples of uncritical animal studies and then proceeds to consider more critical engagements - Critical Animal Studies (CAS) and Feminist Animal Studies (FAS) which I see as only partially overlapping projects. Having set out a politicised and non-politicised approach, the paper muddies the waters in the later sections. While different approaches may attempt to tell us 'how things are', and critical perspectives are particularly concerned to open up grounds for intervention and demonstrate a commitment to both revealing and changing the suffering of many non-human animals, the answer to the question of 'what is to be done' is not a straightforward one.

\section{Uncritical animal studies}

At a symposium some years ago, a keynote talk by a speaker who had been writing about the cultural history of the elephant, subjected the audience to pictures of elephants which had been killed as hunting trophies. During the paper, a critical animal sociologist who was unfortunate enough to be sitting next to me and my irritated muttering, passed a note which said: "this is uncritical animal studies". Indeed it was. The paper raised no questions about the mass killing of elephants and it had nothing to say of the gendered, classed and imperialist context of this form of human 'entertainment'. It merely told us that some people in the late nineteenth and early twentieth century killed elephants for sport and that elephants often had to be shot very many times before they died. This section of the paper considers some more plausible examples of uncritical animal studies that are distinctly sociological.

One important way of drawing species into sociology has been in terms of understanding the process of historical change through formations of human 
relations with non-human animals. Historical accounts have used modernity as a framework for theorizing human relations with non-human animals, mapping changing attitudes towards animals accompanying the dramatic changes of transition in European modernity, from relations of dependency, contingency, and religious inspired anthropocentricity to those of distance, sentimentality and ambivalence in more secular times (Thomas, 1983: 166-67).

Least controversial for the disciplinary mainstream is a sociology which considers human relations with non-human animals to be relevant in that they are revealing about human beings themselves. Tester's (1992) sociology of animal rights for example, concentrates on imposition of social relationships through regulation of human relations with other animals. He draws on the work of Elias in suggesting that the development of anti-cruelty legislation was part of the 'civilizing process' to discipline the working class (Tester, 1992: 68-88). Tester argues that how we think about animals does not tell us about the ontological condition of animals, but about ourselves, thus animal rights "is a morality about what it is to be an individual human who lives a social life" (1992: 16). Animal rights has nothing to do with any concern for sufferings humans may inflict upon animals, but is about humans making themselves feel 'good' as moral agents arguing for those who cannot argue for themselves (1992: 78).

A slightly less anthropocentric account is provided by Franklin (1999) who contends we have recently seen significant qualitative changes in species relations as the categorical boundary between human and other animal species has been challenged with 'postmodernization'. Modernity defined humans as rational, capable of self-improvement and potential goodness, and established clear boundaries between humans and animals. From the seventeenth to the twentieth centuries, animals were treated primarily as a resource for human improvement, so that meat eating and the use of animals in research became standard practices. As we move towards postmodernity however, 'misanthropy' has become a feature of 
social life as we collectively reflect on our destruction of the natural world. Animals are also associated with a sense of 'risk'; which can be seen in food scares, or concerns about the preservation of 'wildlife'. Finally, individuals suffer 'ontological insecurity' due to a depletion of family ties, sense of community and neighbourhood with changes in domestic relations (increased divorce rates and re-marriage) and patterns of employment ('flexible' labour markets and less job security).

Consequently, people look to relationships with pets to provide stability and a sense of permanence in their lives (1999: 36). Thus Franklin suggests that we are developing 'increasingly empathetic and decentred relationships' with other species evidenced across a range of sites of human-animal relations - from entertainment to food, 'pet' keeping to hunting (1999: 35). There are significant empirically unsubstantiated sociological assumptions here; for example, that certain social changes (such as those in the family) have led to certain practices (like more people keeping pets), and that the reason people do so is to provide security. Second, whilst human relations with animals have undoubtedly changed, there have been different and competing conceptions of how humans can relate to other animals and both continuity and change in material practices. A model of increasing sentimentality ignores the contradictions embedded in our relations with animals and the different kinds of relations humans have with specific species.

There is certainly merit in such observations that animals are coconstitutive of human social arrangements, and that these relations change over time. What makes these examples of uncritical animal studies however, is that they evade consideration of the power relations articulated through such relationships. It is this focus on power and an identification with non-human animals as victims of forms of systemic human domination through which they are oppressed and exploited, that has led to the articulation of more critical approaches to the study of human-animal relations. As the founders of the Journal for Critical Animal Studies (Best et al, 2009) claim, what distinguishes critical 
approaches is that they actively critique mainstream approaches in human-animal studies and they take a standpoint 'for' non-human animals.

\section{Critical Animal Studies, Feminist Animal Studies and intersectionalised emancipation}

In thinking about the development of critical approaches in animal studies, we have to consider the philosophical influences on the contemporary animal advocacy movement. Singer's Animal Liberation (1990), first published in 1975, argued for the irrationality of 'speciesism', a prejudice which licences exploitative and oppressive practices that harm sentient beings. On the basis of utilitarianism, Singer argued that we should account for the interests of non-human animals, restrict the harms we subject them to and maximise their welfare. Objecting to Singer on the grounds that non-human animals have an interest in not being used for human ends, Regan (1983) developed a rights-based approach to our relations with other species claiming that many higher animals should be free from human abuse, use and interference on the grounds that they are 'subjects-of-a-life' (with interests, desires, a sense of themselves over time) and thereby had rights. As Cochrane (2012: 7) has remarked, the debate over animal interests versus animal rights has been focused on and continues to be polarised by, this Singer/Regan debate.

Feminism was engaged with issues of human relations with non-human animals from the early second wave (see Adams, 1976). In early works, some claimed that women's social practices of care mean they are more likely than men to oppose practices of harm against animals (Salamone, 1982); or that women may empathize with the sufferings of animals as they have some common experiences; for example, female domestic animals are most likely to be 'oppressed' via control of their sexuality and reproductive powers (Benny, 1983: 142). A key strand of writing focused on gender roles, an 'ethic of care' and concern for non-human species, and 
an important theme in early writings is that female values are a product of a different socialisation process and a different placement in the public and private division of labour. In ecofeminist writings in the 1980s this involved some claims that female socialisation inculcates characteristics of nurturance, sympathy, empathy and "feeling the life of the other" (Plant 1989: 1). Feminist critics like Mellor consider the patriarchal division of the human Western world into feminized private and masculinised public spheres involves, "an imposed altruism" (1992: 251), which does not extend empathy beyond family members. Donovan (2006) suggests however, that such critics have misunderstood ecofeminist care theory. Discussing the case of non-human animals as subjects of feminist concern, she argues that it is not

a matter of caring for animals as mothers (human and non-human) care for their infants as it is one of listening to animals, paying emotional attention, taking seriously - caring about - what they are telling us. (2006: 305)

This implies a relational notion of species. Recently, Gruen (2015) has argued for the further development of a relational notion of the self, incorporating responsiveness and responsibility for the well-being of all creatures, informed by 'entangled empathy'. For Donovan however, understanding the "qualitative heterogeneity of life forms" implies dialogical reasoning and the articulation of a non-human standpoint by feminist animal advocates (2006: 306-7).

The feminist critique of animal rights debates were that they failed to attend to the overlapping of intra-human forms of oppressions and exploitation with those in which non-human animals were caught. Whereas utilitarianism and animal rights theory has often scorned empathy and compassion as an unstable basis for ethical claims (Garner, 2005), feminist animal studies (FAS) has been sceptical of the deployment of enlightenment rationalism in the development of a 
universal ethics for the human treatment of non-human animals. Rather, it is via our attentive observation and our compassion, even for creatures who might appear alien to us, that we might enter into 'dialogue'. Donovan makes clear that attention and empathy must be accompanied by political engagement - through an analysis rooted in intersectional understandings of power and through advocacy which resists the objectification of animals and asserts their likely 'point of view'.

While Gaard (2012) is right to observe that the intersectionalised observations of FAS scholarship were ignored by much work in human-animal studies for twenty five years, there is now increasing discussion of 'entanglements' of oppression (Nibert 2002). The development of 'critical animal studies' (CAS) has sometimes drawn clearly on FAS and ecofeminist understandings of intersectionality and promoted the awareness of interlinked forms of domination, inequality and hierarchy, alongside a need for advocacy. Booth (2011: 329) has described Critical Theory as "for the potential community of mankind and for the purpose of emancipation". In a recent paper, Author and I (Author and Author, 2015) argue for a critical posthumanism that is for all that lives, and for the purpose of eliminating multiple forms of oppression. Whilst this chimes with advocacy of 'total liberation' in CAS (Best, 2010), a notion reflected in the work of some ecofeminist scholarship (see jones, 2014), it is not entirely clear what advocacy of eliminating oppression or securing various liberations might entail, a point to which we will return.

CAS has been hostile to uncritical approaches in human and animal studies which might critically discuss the problematic boundaries of human and animal, but tend not to problematize the systemic relations of social power which profoundly shape the lives of non-human animals. A case in point here would be Haraway, whose work Weisberg (2009) has criticised for its 'intricate word play' that pays lip service to the problematics of the human/animal binary, eschews activism opposing animal exploitation and continues to justify exploitative practices. There are 
divergent perspectives in the nature and quality of scholarly engagements with activism, with some more keen to promote synergies than others (respectively, Best et al. 2009 and Nocella et al 2014; and McCance 2013). Despite this, the notion that scholarship be critically engaged with undermining institutions of animal oppression has brought a wide range of scholarship for multiple disciplines under the banner of a CAS, which challenges the "intricate interrelationship" of "hierarchical power systems" within which humanity and the natural world are exploited (Best 2007: 3).

Some feminist work has allied itself strongly with a politics of animal rights and a stance of 'total liberation' (jones, 2014). But within feminist animal studies there tends to be more tolerance of a diversity of theoretical perspectives and practical political engagements. As a recent special issue of Hypatia on 'Animal Others' illustrates, there are a variety of positions some more closely allied to radical perspectives (Gaard 2012) and others to postmodernism (Stanescu 2012). What binds them is the appreciation of the precarious nature of animal lives, embodied materialism and a commitment to intersectional analysis. Whereas CAS has until recently marginalised feminist accounts, and often prioritises the impact of capitalism in apparently intersectional analyses (Nibert 2002; Torres 2007), FAS has produced rich accounts of the gendering of species, albeit that some work has underplayed other elements, such as the importance of race and culture in structuring species based oppression (Deckha 2012).

Feminist animal studies scholarship may well be more tolerant of diversity not just because of the plethora of feminisms, but also because there has been a concerted attempt to disturb the human/animal binary through a critique of liberal humanism and the articulation of different kinds of positions on embodiment and materiality. This is a very different trajectory from that of animal rights/liberation which has tended to try and empty moral theory of its humancentric biases whilst still holding fast to anthropocentric humanisms moral and methodological 
commitments to reason (Diamond 2008). Thus a further difference between feminist and non-feminist critiques of human-animal relations is that feminism has been far more attentive to the ways anthropocentric humanism, ironically, influences debate on what emancipation for other animals might mean.

Abolitionists like Francione (2000) argue that liberation means that domesticate animals must cease to be - having been bred into a state of dependency and indignity and lacking any viable ecological niche. For Plumwood (2000) however, humans have always been part of co-constitutive relations with other species, domestication cannot be entirely read as some original state of 'fall'; and for Davies (1995) feminist concern for domesticate animals involves learning from them and appreciating their lifeways, not dismissing them as "inauthentic". The Francionist position articulates the problematic dualism of civilization and wilderness in Plumwood's view, or a gendered denegration of the 'tame' or domesticated (and thereby feminized) for Davies. Here, I think that we see Francione articulating a liberal humanist understanding of what liberation for animals might mean, while feminist approaches question presumptions of authenticity and the autonomous self (human or animal) in the liberal humanist frame of liberation. Emancipation in this feminist critique is not about freedom from constraint but about re-situating humans as ecologically embedded and embodied subjects of interspecies communities. FAS scholarship tends to articulate therefore, an embodied, affective, relational ontology.

There have been disputes however, from within FAS. Plumwood (2000, 2004) claims the 'ontological veganism' of Adams (that is, a position advocating individual abstention from all use of animals) is universalist and ethnocentric. Such advocacy presumes that, unlike other species, humans can place themselves outside or above nature in avoiding the use of animals that is part of the human condition as ecologically embedded beings. As an alternative Plumwood proposes 'ecological animalism', wherein a critique of the human exploitation of animals is 
combined with respect for different cultural meanings of certain practices (such as the hunting and eating of animals). Much rests here on how Plumwood reads Adams (1994a) as positing veganism as a universal truth, rather than a culturally situated tactic. Whilst Adams does not always foreground her work as culturally delimited, it is clear that, taken as a whole, her critique is aimed at the commoditisation of animals-as-meat in Western developed cultures, and she sometimes does spell this out very clearly (1994b: 83). In addition, Plumwood has her own universalist ontology here in respect of the inevitability of meat consumption in all cultures (Eaton, 2002). Nevertheless, Plumwood's 'ecological animalism' is an attempt to reflect intersectionalised politics and understandings of the world, despite the rather misplaced attack on Adams as a vehicle for delivering this.

My own preoccupations in FAS have been with developing sociological frameworks for the understanding of human-animal relations, elaborated by empirical studies of domesticate animals used for food and companionship. Human relations with other species are constituted by and through social institutions and processes which I have conceptualised as sets of relations of power and domination, which are consequential of normative practice. These interrelate to form a social system of human domination that I refer to as 'anthroparchy' (Author, 2005, 2011a). In addition, species relations are intrinsically co-constituted with other kinds of complex forms of domination (such as patriarchy, capitalism and colonialism) and assume specific spatialized and historical formations.

Human domination therefore, is differentiated, and there are varied degrees of domination of other species by humans. I use the concepts of oppression, exploitation and marginalisation in order to describe this. I use the term 'oppression' to describe a harsh degree of relations of dominatory power which has speciesspecific application - some species can be oppressed (such as farmed animals) and others cannot (such as intestinal flora). 'Exploitation' refers to the use of something 
as a resource, for example, the exploitation of farmed animals for labour, skin, fur, flesh and other products, or the use of animals in guarding and herding. 'Marginalization', I apply to the rendering of something as relatively insignificant, and has a similar meaning to humancentrism. There is diversity in the form and degree of human domination. For example, intensive forms of production in animal agriculture can be seen as extreme or strongly oppressive institutional sites. It is unlikely that all animals 'used' by humans experience domination in the same way, although there are strong similarities in the ways in which processes of domestication affect both companion and farmed animals. The oppressive experiences of farmed animals may be very different from that of prized 'working animals'. The lives of animals kept as 'pets' are often very different from those of farmed animals, but there is also evidence of cruelty, neglect and abandonment of animals by their human 'companions', and of industrial modes of exploitation in breeding (Author, 2011b). Both the range of differences and similarities in human relations with non-human animals need to be considered in developing a culturally sensitive, intersectional and species-differentiated approach to advocacy.

Reflecting feminist critiques of the rationalist humanism framing approaches to animal rights and animal liberation, interventions focused on how we (humans) might live well with other (minded) animals seem more prescient than arguing for 'liberation', 'emancipation' or animals as 'rights' bearing individual subjects. In developing a politics which contests oppression, it is important to remember that the concepts of liberation, emancipation and rights draw very heavily on the same European Enlightenment humanism which informed a model of political and cultural universalism that has had disastrous consequences for many peoples and non-human lifeworlds. While much has been written to effectively critique the liberal humanist underpinnings of colonialist and imperialist endeavours in the eighteenth and nineteenth centuries, liberal humanism persists still in the language of animal rights, just as it undergrids notions of human rights. But does a 
problematizing of the liberal and Enlightenment foundations of emancipatory agendas mean that they cannot be disentangled from the imperialist missions and human-centred humanism? This needs to be carefully negotiated. Many of us working within CAS/FAS wish to advance an agenda which opposes the domination of life in all its variety. Yet as emancipatory politics has learned to its cost, conceptions of liberty, rights, wellbeing and so on are fraught with contradiction, and this is why an emphasis on the intersectional qualities of domination is so important. What unites various forms of critical scholarship is an understanding of 'humanity' as embedded in networks of relations of dependency with the nonhuman lifeworld, and seeing the fragility of embodied life, both human and nonhuman. So then, with this in mind, what kinds of social changes might animal sociologists be concerned to promote?

\section{Sociology for other animals}

At the turn of the $21^{\text {st }}$ Century, Shapiro (2002 p. 332) claimed that 'animal studies' had made 'modest gains' in improving the situation of non-human animals. There are those in uncritical animal studies who may agree that we have seen some positive changes, for example in the UK or the EU in terms of 'improvements' in farmed animal welfare and the mainstreaming of ideas about 'happy' and 'humane' farming and killing (Bock and Buller, 2013). However, in terms of the global spread of intensive models of animal agriculture, the situation for farmed animals was worse (regarding the numbers raised and killed) in 2002 than in 1972, and numbers of animals to be killed for food is predicted to double in the next fifty years, overwhelmingly through the spread of Western intensive methods (Food and Agriculture Organisation, 2002; Mitchell, 2011). The challenge faced by advocates contesting the killing of animals for 'meat' then, is considerable. 
Marcus (2005) argues that there are four contestationary positions which interrogate our current social practices and institutions, and are embodied in current social movement activity: vegetarianism, animal rights, animal welfare and 'dismantlement'. Marcus appears to support an animal rights case for abolitionism the avoidance of all animal use and exploitation, but in fact argues in favour of dismantlement, a term he uses to describe forms of progressive welfarism which works towards the ultimate undermining of the industries of animal agriculture and animal experimentation, disassembled one piece at a time (2005: 79). For Marcus, a gradualist approach might enable the transformation of public opinion through increasing sensitivity to animal welfare. While intensive animal agriculture spreads apace across the globe, welfarist arguments clearly seem to have little traction in arresting the scale of the violence inherent in the raising and killing of non-human animals for food and have secured but minor changes in industrial animal agriculture and only then, predominantly in more developed countries. It can also be argued that that minor welfare gains may function to legitimate the practices of such industries by improving their public image. There is however, little empirical evidence either that welfarism sensitises public opinion to animal abuse, or that it relieves tensions attending current practices, in order to substantiate such positions. Nevertheless, we might consider whether a welfarism of a more critical kind might be a tool through which critical sociological animal studies might engage policy fora on a path to a less oppressive future for non-human animals.

This is certainly the kind of future a critical welfarist such as Marcus hopes for, but for others advocating a welfare agenda, such as Haraway, there is no utopia that can be realised (2008: 106). In Haraway's relativist mode of ethical relating, nonhuman animals cannot be liberated; rather, we must strive for incremental kinds of changes that emerge from the best, most caring and reflexive of human-animal interactions that take the animals' point of view seriously. While such sentiments might be laudable, Haraway's view of what this might actually entail does not 
reflect most FAS understandings of what care, respect and flourishing for nonhuman animals might mean in practice. She suggests, for example, that we might enrich the lives of laboratory animals and farmed animals as far as we are able, and kill them as kindly as we can. Her preferred notion of ethical eating and living with Other animals owes more to Michael Pollans' 'locavorism', a minimally welfarist position unsubstantiated on environmental grounds (see CIWF, 2002), and often embedded in both social and political conservatism (Stănescu, 2010). It is only marginally disruptive to the humancentric discourse and practices of animal agriculture and animal foodways.

Francione's (1996) objection to welfarism, even that more radically intentioned such as the 'new welfarism' of Marcus, is that it reinforces the legal status of animals. As long as animals are property, he claims, human interests will always outweigh those of any animal, individually or collectively, and however slight the issue of conflict. Welfarism therefore, does not challenge the foundational logic of the social domination of species. In this, Francione is right, but he problematically assumes here that social reality is constituted by and through law. In addition, given the investment of states and state-like international organizations in animal agriculture, to place faith in the state as potentially transformational in tackling human species domination is misplaced optimism. Welfarism is certainly a rearticulating of species domination through pastoral rather than disciplinary power (Cole, 2011). However, whether concerns for welfare and legal change can never be disruptive to species relations is less certain. There may be some rapprochement between interventions if the language used to describe such practices was less polarised across a welfarist-liberation dualism, and if we considered more concretely what kinds of shifts in human relations with non-human animals might be supported from a critical sociological standpoint.

In terms of what substantive change might look like, an important sociological basis for thinking about this is to consider what matters for what species 
in which context of social relations. While Bests' notion of 'total liberation' may be a political rallying cry for those of us interested in intersectionality and radically reconfiguring human-animal relations, it does not specify what is to be done. Recent publications in CAS (for example, Nocella et al, 2014) contain a range of interesting contributions which all skirt in different ways around the question of intervention and of academic advocacy. Some suggest a politics of 'groundless solidarity' in which,

one does not attempt to take power or impose a hegemonic mindset on others, but...create[s] space for others to have autonomy. This means that we must....struggle to help non-humans create spaces where they can flourish and develop their own organic relations and communities (Colling, Parson and Arrigoni, 2014: 68).

What does such radical talk mean, however, in terms of what interventions might be supported? Colling et al go on to say that fighting against institutions that imprison, abuse and kill non-human animals (like those of farming and experimentation), supporting those animals who "resist their human oppressors" (such, perhaps, as those escaping from farms or slaughterhouses), and stopping the geographic marginalisation of wild animals. But this is not 'liberation' in the conventional sense as deployed in Western political theory. Supporting farmed animals through the sanctuary movement is a demonstration of care and respect for animal-being, rather than an act of liberation in which non-human animals are set free.

Jenkins and Stănescu (2014: 76-83) articulate an 'engaged veganism' as an agenda for change. But while this clearly demonstrates political commitments to intersectional emancipation, it certainly does not appreciate the complexity of intersectionality in social movement praxis or in human lifeways. They reject any form of welfarism as apologia for human abuse of domesticate animals and 
consider anything less than a total liberation perspective as somehow cancelling any political standpoint - feminists who participate in animal abuses are therefore, 'not' feminists. Despite their caveats, it seems that Jenkins and Stănescu can determine the parameters of an intersectional politics and that what liberation for animals might mean is straightforwardly apparent. In the same volume Drew and Taylor (2014: 170-171) indicate however, that this is rather more difficult by asking how CAS scholarship might 'know' what animals might desire in terms of our research methods and our advocacy. That, for example, mammals seek to avoid pain, and that they are bored when severely confined seems incontrovertible as an agenda for change. This might be supported, I would hope, by sociological analysis of disciplinary institutions in perhaps an interdisciplinary frame where people who know more about reading the behaviour of non-humans than most sociologists might contribute. For other kinds of animals, particularly those less known and more alien to us, the task is more challenging.

In addition to questions of epistemology, our language for change which is part of the difficulty. Cochrane (2012) offers a convincing case for animals having 'rights' without being 'liberated', and his ethical arguments preclude much of the current treatment of non-human animals which CAS scholarship advocates against. While I am not quite convinced we need a notion of 'rights', FAS scholars in particular might be sympathetic, sceptical as many are of projects for 'liberation' cast in mould of Enlightenment humanism (see Braidotti, 2013). Much posthuman thinking suggests that there is no autonomy - the liberal subject, be it human or non-human, is a myth and we are embedded in this world of diverse being, together. Perhaps then, a move away from conceptions of 'liberation' or of 'rights' or of 'welfare' might provoke a less divisive and more nuanced discussion of what desirable transformations in human relations with other animals might look like.

In researching various kinds of social practices, critical sociologists can illuminate the kinds of social institutions and practices in which certain species of 
animals are embedded with humans and tease out the nature of oppressive practices. Herein, they might be able to suggest interventions in the normalisation of the practices of animal abuse which are so embedded in the cultures of more developed countries that they are rarely questioned. These might include, for example, raising questions about the normativity of socialising children into anthroparchal understandings of human relations with non-human animals, such as the normativity of everyday 'meat eating' (Cole and Stewart, 2014); or raising questions about 'animal agriculture' for predominant discourses around sustainability (Twine, 2010).

An adequate sociological understanding of systemic domination cannot elide different forms of domination and degrees of exploitation and oppression. We need to consider nuanced differences in human relations with different kinds of animals in different social contexts. Like others working in critical/feminist animal studies, I consider that human relations with non-human animals should be understood as assuming multiple and interlinked forms that can be understood as systemic. However, while there are links between more and less benign/abusive relations, differences need to be conceptualized. I do think, though many in CAS might disagree for example, that companion species relations, for example, between some humans and dogs are a glimpse of what can and might be, and a small opening into a world of potentially fruitful species cohabitations. Positive engagement with difference exists despite a social reality of dogs as 'pets', commodified and objectified as property; and notwithstanding the clear links between the keeping of non-human animals as companions in the home, and profit for animal agribusiness through the consumption of 'pet food'.

Where sociology has responded to HAS, it has often done so in specific arenas of interaction such as home, food and eating or rurality. There needs to be an expansion of the inclusion of research on human-animal relations into areas such as 'work' and the labour process, globalization and the scope of social theory must be more-than-human. Critical scholarship can suggest processes and 
practices in which specific species are caught and through illuminating social forms might suggest a diversity of ways in which less benign human practices might be addressed. In doing so, we might build up from progressive reform as a starting point in terms of engagement with the polity through policy intervention. There will be possibilities for more transformative and critical work with social movement organizations and public engagement (such as vegan outreach). In addition, the continual expansion of animal studies is (slowly) shifting academic agendas, for example, through the mainstreaming of critical approaches to animal studies stressing the importance of intersectional analysis.

\section{Conclusion}

We live in a complex world of multiple social relations and an important contribution of sociology has been the increasingly sophisticated mapping of the way these interact. These are of utmost relevance to understanding the social forms which our relationships with non-human animals take. This paper has urged sociologists in general to consider 'the animal', and animal sociologists to think more critically and also to be open to a range of forms of advocacy. We live in the age of the Anthropocene and there is no escaping the human. We also are embedded in this life together with multifarious other species. A critical and sociological analysis of human relations with non-human animals can provide us with the tools for the theorisation of species in terms of human domination, exploitation and oppression, while remaining sensitive to differences in the kind and degree of human practices. Being critically sociological, it should be underpinned by the conception that the oppressions of human and non-human animals are intersected. Finally, a critical sociology of species must be an engaged sociology, a call to action which grounds its attempts to theorise, document and explain the world in the context of political struggles to change it. The intersection of inequality and difference means that human populations, communities and 
individuals are differently placed in responding to choices of how they interact with the multiplicity of non-human species of 'animal'. Sociological animal studies of kinds still need to reflect this more deeply, but critical animal studies scholarship in particular might emphasize securing change through transformation in human social relations with other animals, rather than a politics of species separatism.

I have argued here for an advocacy agenda that is open to various forms of engagement. I do think that in terms of policy innovation, the state and international organisations are conservative and difficult to challenge and that an agenda of nonhuman animal 'welfare' is probably a necessary starting point. It is also a starting point that might lead elsewhere as there is more possibility for engaging with transformatory agendas in civil society and in working alongside and within social movement organisations. Any agenda for change must be situated in localities with varied cultures and conditions and here, careful studies of specific sites of humananimal relations and particular formations of the human use of other animals, will be of great value.

\section{Bibliography}

Adams, C. J. (1976) 'Vegetarianism: the inedible complex', Second Wave 4, 4: 3642.

Adams, C, J. (1994a) 'The feminist traffic in animals' in G. Gaard (ed.), Ecofeminsm, Women, Animals, Nature (1993), Temple University Press: Philadelphia.

Adams, C. J. (1994b) Neither Man nor Beast, New York: Continuum.

Benny, N. (1983) 'All one flesh: the rights of animals', in L. Caldecott and S. Leyland, S. eds. Reclaim The Earth, The Women's Press: London. Best, S. (2007) 'Introduction', Journal of Critical Animal Studies 5, 1: 2-3. 
Best, S. (2006) 'Rethinking revolution: animal liberation, human liberation and the future of the left', The International Journal of Inclusive Democracy 2, 3: 1-24.

Best, S., Nocella II, A. J., Kahn, R., Gigliotti, C. and Kemmerer, L. (2009) Introducing Critical Animal Studies retrieved from: http://www.criticalanimalstudies.org/wpcontent/uploads/2009/09/Introducing-Critical-Animal-Studies-2007.pdf

Best, S. (2010) 'Animal liberation, human liberation and the future of the left', retrieved from http://www.drstevebest.org/RethinkingRevolution.htm, $21^{\text {st }}$ March 2014.

Bock, B., and Buller, H. J. (2013) ‘Healthy, happy and humane: evidence in farm animal welfare policy', Sociologia Ruralis, 53(3): 390-411.

Booth, K. (2011) Realism and World Politics. Routledge: London.

Braidotti, R. (2013) The Posthuman. Cambridge: Polity.

Burowoy, M. (2005) 'For a public sociology', American Sociological Review 70, 1: 428.

Carter, B. and Charles, N. (2011) 'Human-animal connections: an introduction' in B.

Carter and N. Charles (eds) Human and Other Animals: Critical Perspectives. Basingstoke: Palgrave, pp. 1-27.

Charles, N. and Aull Davies, C. (2008) My family and other animals: pets as kin. Sociological Research Online 13, 5 http://www.socresonline.org.uk/13/5/4.html.

Compassion in World Farming (CIWF) (2002) Detrimental Impacts of Industrial Animal Agriculture. CIWF: Godalming, Surrey.

Cochrane, A. (2012) Animal Rights without Liberation. Colombia 
University Press: New York.

Cole, M. (2011) ‘From “Animal Machines" to "Happy Meat"? Foucault's ideas of disciplinary and pastoral power applied to 'animal-centred' welfare discourse', Animals, 1 (1): 83-101.

Cole, M. and Stewart, K. (2014) Our Children and Other Animals: the Cultural Construction of Human-Animal Relations in Childhood, Farnham: Ashgate.

Colling, S., Parson, S. and Arrigoni, A. (2014) ‘Until All Are Free: Total Liberation through revolutionary decolonization, groundless solidarity and a relationship framework', in A. J. Nocella II, J. Sorenson, J., K. Socha and A. Matsuoka (2014) (eds) Defining Critical Animal Studies: An Intersectional and Social Justice Approach for Liberation. Peter Lang: New York, pp. 51-73.

Davies, K. (1995) 'Thinking like a chicken: farm animals and the feminine connection', in C.J. Adams and J. Donovan (eds.) Animals and Women: Feminist Theoretical Explanations. Duke University Press: Durham, N. Carolina.

Dekha, M. (2012) "Toward a postcolonial posthumanist feminist theory: centralizing race and culture in feminist work on nonhuman animals" Hypatia: Journal of Feminist Philosophy 27, 3: 527-545.

Diamond, C. (2008) 'The difficulty of reality and the difficulty of philosophy'. In S. Cavell (ed.) Philosophy and Animal Life, Colombia University Press: New York.

Donovan, J. (2006) 'Feminism and the treatment of animals: from care to dialogue', Signs, 31(2): 305-29.

Drew, L. and Taylor, N. (2014) `Engaged activist research: challenging apolitical 
objectivity', in A. J. Nocella II, J. Sorenson, J., K. Socha and A.

Matsuoka (2014) (eds) Defining Critical Animal Studies: An Intersectional and

Social Justice Approach for Liberation. Peter Lang: New York, pp.158-177.

Eaton, D. (2002) 'Incorporating the Other: Val Plumwood's Integration of Ethical

Frameworks, Ethics and the Environment, 7(2): 153-180.

Food and Agriculture Organization of the United Nations (2002). World agriculture:

Towards 2015/2030: Summary report. Retrieved from

\section{ftp://ftp.fao.org/docrep/fao/004/y3557e/y3557e.pdf}

Francione, G. (1996) Rain Without Thunder: The Ideology of the Animal Rights

Movement. Temple University Press: Philadelphia.

Francione, G. (2000) Introduction to Animal Rights: Your Child or the Dog? Temple University Press: Philadelphia.

Franklin, A. (1999) Animals and Modern Cultures: A Sociology of Human-Animal Relations in Modernity. Sage: London.

Gaard, G. (2012) 'Speaking for animal bodies', Hypatia: Journal of Feminist Philosophy 27, 3: 520-526.

Garner, R. (2005) The Political Theory of Animal Rights, Manchester University Press: Manchester.

Geary, D. (2009) Radical Ambition: C. Wright Mills, the Left and American Social Thought. University of California Press: Berkely.

Gruen, L. (2015) Entangled Empathy: An Alternative Ethic for Our Relationship with Animals. Lantern Books: New York.

Haraway, D. (2008) When Species Meet, University of Minnesota Press:

Minneapolis.

Jenkins, S. and Stănescu, V. (2014) 'One struggle' in A. J. Nocella II, J. Sorenson, J., K. 
Socha and A. Matsuoka (2014) (eds) Defining Critical Animal Studies: An Intersectional and Social Justice Approach for Liberation. Peter Lang: New York, pp. 74-87.

jones, p. (2014) The Oxen at the Intersection: A Collision (or, Bill and Lou Must Die: A Real Life Murder Mystery from the Green Mountains of Vermont). Lantern Books: New York.

Latour, B. (2010) A plea for earthly sciences. In J. Burnett, S. Jeffers and G. Thomas (eds) New Social Connections: sociology's subjects and objects. Palgrave: Basingstoke, pp. 72-84.

MacDonald, M. (2010) 'Foodprints' in The Future of Food, special issue of Resurgence, no. 259, March/April, pp.2-3.

McCance, D. (2013) Critical Animal Studies: an Introduction, SUNY Press.

Marcus, E. (2005) Meat Market: Animals, Ethics and Money. Brio Press: Boston.

Mellor, M. (1992) Breaking the Boundaries: Towards a Feminist Green Socialism, Virago: London.

Mills, C. W. (2000 [1959]) The Sociological Imagination, 40 ${ }^{\text {th }}$ Anniversary Edition, Oxford University Press: Oxford.

Mitchell, L. (2011) ‘Moral disengagement and support for non-human animal farming', Society and Animals, 19: 38-58.

Nibert, D. (2002) Animal Rights/Human Rights: Entanglements of Oppression and Liberation, Rowman and Littlefield: Lanham, Maryland.

Nocella II, A., J., Sørenson, J., Socha, K. and Matsuoka, A. (2014) (eds) Defining 
Critical Animal Studies: An Intersectional and Social Justice Approach for

Liberation. Peter Lang: New York.

Peggs, K. (2014) 'From centre to margins (and back again): critical animal studies and the reflexive human self', in N. Taylor and R. Twine (eds.) From the Margins to the Centre? The Rise of Critical Animal Studies. Routledge: London.

Plant, J. (1989) Healing the Wounds: The Promise of Ecofeminism, New Society

Publishers: Philadelphia.

Plumwood, V. (2000) 'Integrating ethical frameworks for animals, humans and nature: a critical feminist eco-socialist analysis' Ethics and the Environment, $5(2)$, p.285-322

Plumwood, V. (2004) 'Ecofeminism' in R. White (ed.) Controversies in

Environmental Sociology, Cambridge University Press: Cambridge.

Regan, T. (1983) The Case for Animal Rights, University of California Press: Los Angeles.

Salamone, C. (1982) 'The prevalence of natural law within women: women and animal rights', in Reweaving the Web of Life: Feminism and Non-violence, Ed. P. McAllister. New Society: San Francisco, pp. 364-75.

Shapiro, K. (2002) Editors Introduction 'The state of Human-Animal Studies: solid at the margin!', Society and Animals, 10,4: 331-337.

Singer, P. (1990) Animal Liberation, Picador: London. First published in 1975.

Stanescu, J. (2012) 'Species trouble: Judith Butler, mourning and the precarious lives of animals', Hypatia: Journal of Feminist Philosophy 27, 3: 567-582.

Stănescu, V. (2010) “Green' Eggs and Ham? The myth of sustainable meat and the 
danger of the local', Journal for Critical Animal Studies, 8 (1-2): 8-32.

Steinfeld, H., Gerber, P., Wassemaar, T., Castel, V., Rosales, M. and de Haan, C. (2006) Livestock's Long Shadow: Environmental Issues and Options, United Nations Food and Agriculture Organisation: Rome.

Stewart, K. and Cole, M. (2009) The conceptual separation of food and animals in childhood. Food, Culture and Society 12(4): 457-476.

Summers, J. (2008) The Politics of Truth: Selected Writings of C. Wright Mills. Oxford University Press: New York.

Taylor, N. and Signal, T. (2011) Theorizing animals: Re-thinking Humanimal Relations. Leiden: Brill.

Tester, K. (1991) Animals and Society: The Humanity of Animal Rights. Routledge: London.

Thomas, K. (1983) Man and the Natural World: Changing Attitudes in England 15001800. Allen Lane: London.

Torres, B. (2007) Making a Killing: The Political Economy of Animal Rights. AK Press: Oakland, Ca.

Twine, R. (2010) Animals as Biotechnology: Ethics, Sustainability and Critical Animal Studies. Earthscan: London.

Weisberg, Z. (2009) 'The broken promises of monsters' Journal of Critical Animal Studies, 7 (2): 22-62.

Wilkie, R. (in press, 2013, online first) 'Academic "dirty work": mapping scholarly labour in a tainted mixed-species field Society and Animals. 